\title{
Hipoclorito de sodio como irrigante de conductos. Caso clínico, y revisión de literatura
}

\section{Sodium hypochlorite used as duct irrigation. Clinical case, and literature review}

Marín Botero ML*, Gómez Gómez B**, Cano Orozco AD**, Cruz López S***, Castañeda Peláez DA****, Castillo Castillo EY*****.

\section{RESUMEN}

El tratamiento de conductos está indicado en caso de daño pulpar irreversible; en la actualidad se evidencian considerables avances en cuanto al diagnóstico, tratamiento y mantenimiento de un diente endodónticamente tratado, pese a ello persisten elementos y materiales usados desde sus inicios, como es el caso del hipoclorito de sodio ( $\mathrm{NaOCl}$.).

El objetivo principal de este artículo será enfatizar en los riesgos y las secuelas ocasionadas por el uso de este irrigante y documentar un caso clínico de una reacción anafiláctica severa por su uso, el manejo dado, además se realizara una revisión de la literatura.

PALABRAS CLAVE: Anafilaxia, reacción alérgica, accidente, hipoclorito de sodio, tratamiento endodóntico.

\section{ABSTRACT}

Endodontics is a treatment that is required after the irreversible pulpal damage. At present, there has been considerable progress in the diagnosis, treatment, and maintenance of an endodontically treated tooth. Despite this there remain elements and materials used since its inception, as is the case of the sodium hypochlorite ( $\mathrm{NaOCl}$.

The main objective of this article is to emphasize the risks and the consequences caused by the use of this irrigante and document a clinical case of a severe anaphylactic reaction by its use, management, in addition there will be a review of the literature.

KEY WORDS: Anaphylaxis, allergic reaction, accident, sodium hypochlorite, endodontic treatment.

Fecha de recepción: 6 de noviembre de 2018.

* Bióloga. Odontóloga especialista en Estomatología y Cirugía Oral. Docente titular Facultad de Odontología. Universidad de Antioquia. Medellín. Colombia

** Odontólogo. Facultad de odontología .Universidad de Antioquia. Medellín.Colombia

*** Estudiante de pregrado de Odontología. Facultad de Odontología.

Universidad de Antioquia. Medellín.Colombia

**** Odontólogo de la Universidad de Antioquia, Medellín, Colombia. Patólogo y Cirujano Bucal Pontificia Universidad Javeriana de Bogotá, Colombia. Profesor instructor Facultad de Odontología Universidad Antonio Nariño.

***** Odontóloga. Especialista en Periodoncia. docente ocasional Universidad Nacional de Colombia.

Bogotá D.C. Colombia. 
Fecha de aceptación: 9 de enero de 2019.

Marín Botero ML, Gómez Gómez B, Cano Orozco AD, Cruz López S, Castañeda Peláez DA, Castillo Castillo EY. Hipoclorito de sodio como irrigante de conductos. Caso clínico, propuesta terapéutica, y Revisión de literatura. $2019 ; 35,(1): 33-43$.

\section{INTRODUCCIÓN}

Cuando es necesario un tratamiento de conductos, el procedimiento debe acercarse a condiciones de perfección, con el fin de evitar un proceso infeccioso secundario a la patología inicial y/o la formación de una lesión radicular. Un elemento considerado como parte del factor de éxito es el irrigante del conducto durante el tratamiento, el cual idealmente debe eliminar microorganismos, "detritus de la instrumentación y disolver restos orgánicos", virtudes químicas que tiene el hipoclorito de sodio en concentraciones entre 0.5 y $5.25 \%$, y es sabido que a mayor concentración mayor capacidad para disolver tejidos ${ }^{1}$. Ello, unido a su bajo costo, ha generado mayor uso. En su contra, hay que destacar la posibilidad de generar reacciones anafilácticas de leves a severas, quemaduras y necrosis de tejidos blandos y duros y lesiones neurológicas.

El uso del hipoclorito data desde la primera guerra mundial, donde se usó en una concentración al $0.5 \%$ para limpiar heridas contaminadas y desde 1920 como irrigante intra conducto radicular ${ }^{2}$. El uso del hipoclorito se masifica antes que surgieran los antibióticos cuando no existían muchas posibilidades de combatir los microorganismos, y aún persiste su empleo a pesar del gran avance de la medicina antibiótica - en 1928 Alexander Fleming descubre la penicilina- y de los efectos deletéreos que ha causado en tejidos vivos.

\section{Presentación del Caso}

Paciente de 58 años que acude al Servicio de Urgencias de la Facultad de Odontología de la Universidad de Antioquia, por presentar dolor a nivel del 11. Como antecedentes odontológicos presenta carillas estéticas en dientes anteriores con resina.

Previa firma de consentimiento informado, se

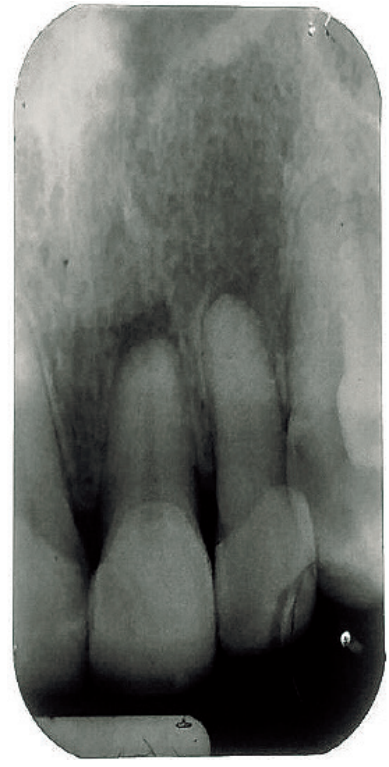

Figura 1. Rx preoperatoria del caso clínico de la paciente que presentó reacción anafiláctica. Se aprecia lesión radio lucida a nivel del 11 y 12. toma radiografía periapical en donde se observa lesión radio lúcida en 11 y 12 siendo mayor la del 11 (Fig. 1).

Se procede a realizar el desbridamiento pulpar del 11 implementando aislamiento absoluto con dique de goma; posteriormente se conforma la apertura cameral y se determina una conductometría tentativa de $17.5 \mathrm{~mm}$, se comienza a instrumentar el conducto con lima 15 . Seguidamente se inicia la irrigación del conducto con hipoclorito de sodio al 5,25\% con adecuada succión. Inmediatamente a la instilación del irrigante, la paciente grita y relata que sintió una sensación urente en el paladar como si le hubieran inyectado un caustico a nivel óseo, y refiere dolor subjetivo que aumentaba conforme pasaban los minutos. Los signos de anafilaxis aparecen rápidamente, se produce un edema visible en los labios que es progresivo y se difunde hacia orofaringe, acompañado de dolor pulsátil en la cabeza, signos evidentes de mareo y disnea. Inmediatamente se suspende el procedimiento y se remite al Hospital San Vicente Fundación, el cual es un centro de cuarto nivel cercano. La paciente es recibida por cirugía maxilofacial en urgencias con signos vitales estables, escala subjetiva de dolor 8 ( escala de 1 a 10) y orientada en tiempo, espacio y persona. La paciente es hospitalizada con diagnóstico de edema angioneurótico, y de inmediato se aplica $0.5 \mathrm{mg}$ de Adrenalina IM, además se genera un plan de manejo con Difenhidramina 

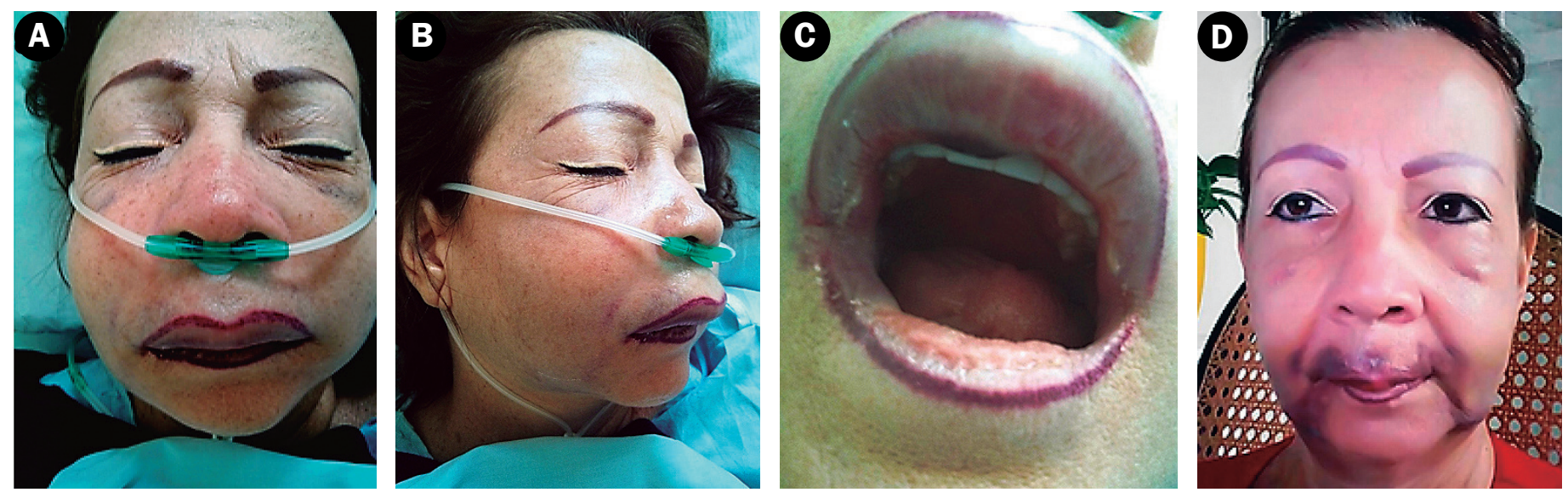

2A. Paciente hospitalizada 24 horas después donde se aprecia el gran edema que compromete espacios faciales primarios y secundarios, 2B. el color de la piel empieza a reflejar señales de hemolisis notándose un color parduzco a nivel de espacio maseterino y región basal del cuerpo mandibular. 2C. Gran edema de los labios, empiezan a aparecer regiones áureas como signo de necrosis.

2D. Hematomas en tercio facial inferior 15 días después de la reacción anafiláctica.

$50 \mathrm{mg}$ cada 12 horas, Hidrocortisona 50mg cada 6 horas, Tramadol 50mg cada 6 horas, Ranitidina $50 \mathrm{mg}$ cada 8 horas, Diclofenaco $75 \mathrm{mg}$ cada 12 horas, Katrol IV, suministro de oxígeno y vigilancia continua de las vías aéreas. Después de estabilizar la paciente fue ubicada en la unidad de cuidados intermedios, debido a que el proceso no se veía revertir y por el contrario parecían aumentar los signos y síntomas, y finalmente se realiza interconsulta por toxicología quien considero que no existía antídoto para este tipo de intoxicación.

Después de 48 horas de hospitalización las áreas que presentaban mayor edema alrededor de la boca se transformaron en un hematoma, posiblemente debido a una vasculitis con hemólisis, con posterior perdida de los desmosomas de las células endoteliales -lisis vascular-, generado por la acción misma del hipoclorito sobre los vasos sanguíneos (imagen 2 a; frontal, b: lateral, c: boca abierta). Quince días después aún persiste parte del hematoma (figura $2 \mathrm{~d}$ ) Dicho suceso se apreció principalmente en los bordes del labio superior, extendiéndose por los cuerpos mandibulares y difuminándose caudalmente por la orofaringe.

La paciente permaneció en hospitalización 4 días en total y se le programaron controles periódicos. La endodoncia fue concluida un mes después, donde se irrigó con clorhexidina al $0.2 \%$ y se colocó hidróxido de calcio $(\mathrm{CaOH})$ intra conducto luego de la instrumentación biomecánica.

\section{REVISIÓN DE LA LITERATURA.}

\section{Anafilaxis, Características y Manejo}

"La anafilaxia es una reacción alérgica sistémica severa, potencialmente fatal, que requiere pronto reconocimiento y atención inmediata y que ocurre de repente después del contacto con una sustancia que causa alergias"3,4, definición tomada del Simposio NIAID-FAAN donde se establece que para que se considere anafilaxis debe cumplir al menos con algunos de los siguientes criterios: a) signos cutáneos y respiratorios o disfunción orgánica o hipotensión, b) evidencia de al menos dos órganos o sistemas afectados luego del contacto con el alergeno ${ }^{5}$.

La anafilaxis puede ser inducida por el consumo de alimentos como mariscos, leche de vaca, huevos, pescados, y frutas; también por medicamentos tipo antibiótico como penicilina y analgésico AINES como ASA y muchos otros, por picadura de insectos y también por causa desconocida. Los alérgenos generados por alimentos se presentaron en edades tempranas de la vida, mientras que las producidas por medicamentos son más comunes en adultos ${ }^{5}$. Esta situación requiere atención inmediata, si la atención medica se retrasa puede ocurrir la muerte por un proceso que conduce a un colapso respiratorio o cardiovascular ${ }^{6}$.

Una reacción anafiláctica presenta signos y sín- 
tomas multisistémicos, a nivel neurológico se presenta mareo, desmayo, debilidad, convulsiones; prurito ocular, lagrimeo, enrojecimiento de la conjuntiva, en la vía aérea superior congestión nasal, estornudos, estridor orofaríngeo, edema y obstrucción laríngea; en la vía aérea inferior: disnea, broncoespasmo, taquipnea, funcionamiento de los músculos accesorios, cianosis y falla respiratoria; en el sistema cardiovascular: taquicardia, arritmia, hipotensión, infarto agudo de miocardio y falla cardiaca; en piel eritema, prurito, urticaria, edema angioneurótico, maculas y pápulas pruriginosas; y por último, en del sistema gastrointestinal nauseas, vomito, dolor abdominal, diarrea ${ }^{7}$.

Usualmente las reacciones pueden darse en uno o dos periodos; el $20 \%$ de los casos presenta un periodo asintomático de 1-8 horas pero puede haber un retraso de 24 horas.

En la consulta clínica se ha observado reacción anafiláctica a otros elementos de los ya mencionados como es al látex, el cual es la segunda causa de alergia en ambientes quirúrgicos y la reacción puede aparecer tanto en el paciente como en el profesional de la salud ${ }^{8}$.

\section{CARACTERÍSTICAS INMUINOLÓGICAS DE UNA REACCIÓN ALÉRGICA}

Las reacciones alérgicas atópicas comienzan con una dermatitis al contacto con el material irritativo. Los signos y síntomas pueden aparecer en forma temprana o tipo I y tardía que es la reacción tipo IV mediada por células T. La tipo I es inmediata, mediada por IgE es severa y puede terminar con la muerte. El paciente esta sensibilizado previamente en la cual las células $\mathrm{T}$ ayudadoras inducen a células B para formar anticuerpos específicos a nivel plasmático; tan pronto ocurre el contacto con el alérgeno los antígenos contactan la superficie de los mastocitos y basófilos y estos generan una degranulación liberando los mediadores inflamatorios como histamina, triptasa sérica, prostaglandinas y leucotrienos que son los que producen una reacción desde una urticaria simple hasta una reacción exótica. La triptasa sérica $ß$ es una proteasa almacenada en los mastocitos y su liberación ocurre inmediatamente, presentando su pico a los treinta minutos y posteriormente disminuye en forma gradual $^{8}$.
MANIFESTACIONES CLÍNICAS DE UNA REACCIÓN ANAFILÁCTICA POR HIPOCLORITO DURANTE EL TRATAMIENTO DE CONDUICTOS

Los signos y síntomas relatados en la literatura van desde la quemadura química por contacto directo o por vapores que pueden generar ulceraciones en la córnea del ojo, hasta una reacción anafiláctica. Usualmente estos signos y síntomas varían mucho dependiendo del grado de compromiso facial y de la severidad del cuadro, y de lo inmediato o tardío de la reacción. Generalmente el paciente experimenta Inicialmente dolor severo, o sensación de ardor, edema y hemorragia que puede ser profusa por hemolisis a través del canal radicular o vascular visible a través de hematomas, en los tejidos blandos adyacentes a la pieza tratada. Estos signos también pueden durar según lo intensidad y la prontitud de la terapia instaurada ${ }^{9}$.

El diagnostico se basa en la inspección clínica, cuando el paciente tiene un antecedente de alergia a una sustancia conocida; generalmente los primeros síntomas son cutáneos y respiratorios, e incluyen enrojecimiento facial, urticaria, broncoespasmo, hipotensión, edema laríngeo, entre otros ${ }^{9}$.

Ante cualquier accidente con hipoclorito. Se debe considerar que una acción toxica del hipoclorito no sigue el curso regular de cualquier infección o edema ya que tanto el hematoma como la infección alteran los planos anatómicos normales y que el $\mathrm{NaOCl}$ puede crear sus propios planos en forma desordenada e irregular a través de los tejidos adyacentes ${ }^{9}$.

Dependiendo del contacto puede generar necrosis de tejidos blandos dejando úlceras y alteraciones nerviosas como parestesia, anestesia temporal o permanente y en raros casos hiperestesia. La resolución ha sido variable en los casos reportados en la literatura desde pocos días o semanas hasta daños permanentes dependiendo del compromiso nervioso ${ }^{10}$; también se ha reportado extrusión de hipoclorito al seno maxilar y al conducto dentario inferior. En casos de ingestión de hipoclorito, este podría producir obstrucción de la vía aérea ${ }^{11-12}$. También en algunos casos se ha visto infección secundaria, ya que inhibe la migración de neutrófilos y produce $^{10}$ daño a nivel endotelial y de tejido conectivo. 
Aspectos Relacionados con

EL HIPOCLORITO DE SODIO (NAOCL).

Este irrigante es una sal formada por ácido hipocloroso $(\mathrm{HOCl})$ e hidróxido de sodio $(\mathrm{NaOH})$, usado como primera elección en los tratamientos de conductos radiculares, por sus propiedades antimicrobiana, antimicótica y antiviral, incluyendo el virus de la inmunodeficiencia humana y posee una acción residual que se puede extender hasta 72 horas $^{13}$, comparado con la clorhexidina en gel, tiene mejores propiedades antimicrobianas, disolución de tejidos y remoción de detritos en la porción más apical del conducto radicular ${ }^{10}$.

Es usado en diversas concentraciones que varían entre 2.6 y 5.25; a mayor concentración es mayor su capacidad de disolver tejidos, a su vez, está demostrado que a una concentración mayor de $0,5 \%$ tiene capacidad citotóxica. A $1 \%$ ya posee efecto antimicrobial y puede disolver tejido orgánico, pero en el tratamiento de conductos se usan concentraciones mayores que potencian los riesgos $^{10}$; es así como en la literatura están reportadas diversas reacciones adversas, aunque muchas de ellas están originadas en complicaciones por falta de precauciones en su manejo ${ }^{10}$.

Entre las desventajas más importantes es que tiene un alto poder de toxicidad si entra en contacto con los tejidos blandos, causando primero una inflamación aguda que finalmente resulta en necrosis, excepto en epitelios altamente queratinizados. El efecto final a altas concentraciones $(5,25 \%)$ es hemolisis de ${ }^{11}$ los tejidos orgánicos debido a su Ph entre 11 y 12.5 lo cual causa efectos oxidativos a nivel de las proteínas, hidrolisis y un efecto osmóticamente activo. A nivel vascular aumenta la permeabilidad de los vasos probablemente debido al daño en sus paredes o por la liberación de mediadores químicos como la histamina; estos efectos producen edema y usualmente un sangrado profuso a través del canal radicular, cuando el $\mathrm{NaOCl}$ no es usado adecuadamente por el clínico. Otras complicaciones encontradas son daños al ligamento periodontal a bajas concentraciones, pero la mayoría de los accidentes reportados han ocurrido con soluciones a altas concentraciones (entre 3 y $5.25 \%)^{10}$

\section{Diagnósticos difERENCIALES}

La condición clínica que representa una mayor similitud con la anafilaxis es el enfisema subcutáneo, que ocurre al infundir aire bajo presión a espacios profundos causando neumotórax, neumopericardio, falla cardiaca, falla pulmonar, daño al nervio óptico, o causar obstrucción del flujo coronario, resultando en un embolismo gaseoso cardiaco con consecuencias fatales ${ }^{14}$. En este caso también aparece un edema rápido en cara y a veces en cuello, pero esta última tiende a auto limitarse; lo clásico de un enfisema subcutáneo es que al palpar la zona edematizada, el tejido crepita; el dolor es variable entre leve y agudo y si compromete el cuello puede haber una dificultad para deglutir, disfonía y disnea ${ }^{15}$.

También hay que diferenciar la anafilaxis con un hematoma y un edema angioneurótico, aunque la anafilaxis tiene un cuadro más severo en las manifestaciones cardiorrespiratorias ${ }^{16}$. Adicionalmente debemos diferenciar la anafilaxis con ataque agudo de asma, obstrucción de la vía aérea por cuerpo ${ }^{12}$ extraño, embolismo pulmonar, pérdida de la conciencia; reacción vasovagal, ataque epilépti$\mathrm{co}$, infarto agudo de miocardio y arritmias ${ }^{7}$.

\section{ManeJo de una reacción adversa al NaOCl}

En el manejo inicial del paciente se debe mantener la calma, tranquilizarlo y permitirle que colabore en la solución de la situación; esto facilitara el diagnóstico y manejo temprano, ya sea una quemadura por contacto directo o una reacción alérgica o anafiláctica. Un reconocimiento temprano y un manejo inmediato y agresivo pueden reducir las complicaciones o las secuelas.

\section{Guía de manejo accidente con quemadura}

- Anestesiar el paciente de forma inmediata ${ }^{17}$.

- Si hubo contacto directo con tejidos blandos, lavar con solución salina inmediatamente para diluir el hipoclorito

- Si hay sangrado por el conducto dejar que fluya para que elimine el irritante, pero igual lavar con solución salina; suspender el procedimiento de inmediato, pero sin dejar el diente abierto.

- Infiltrar corticosteroide como Dexametasona o Betametasona en la mucosa vestibular del diente tratado o en el área de la quemadura. Si es en el arco inferior aplicarlo intraligamentariamente por mayor densidad del hueso.

- Si la respuesta es algo más tardía, el paciente debe estar informado de la situación y que él reco- 
nozco el problema y busque ayuda. La prevención es muy importante instruyendo al paciente sobre los signos, síntomas y conducta a seguir en caso de una reacción ${ }^{8}$.

\section{Guía de manejo en reacción alérgica}

- Requiere un manejo básico para suprimir la reacción y prevenir la extensión del cuadro y el deterioro del paciente. Lo primero es eliminar el contacto con el ${ }^{13}$ agente desencadenante ya sea una sustancia ingerida o un elemento en contacto. Ante todo mantener la vía aérea permeable, ojala con oxígeno al $100 \%$ si es posible. Idealmente canalizar una vena para aplicación de líquidos endovenosos de más rápida absorción para controlar los signos vitales, si es del caso hospitalizar. La primera opción es colocar un antihistamínico como epinefrina y tradicionalmente se ha aplicado por vía subcutánea, pero ${ }^{18}$ Simons FER, en una investigación publicada en el 2001, encontró que era mejor el resultado cuando se aplicaba intramuscular. La epinefrina puede ser reaplicada cada 5 a 15 minutos hasta que desaparezcan los síntomas de la anafilaxis o de hiperadrenalismo como taquicardia, disconfor, aprehensión y ansiedad pero bajo estricto control medico ${ }^{18}$. Otra opción de antihistamínico es la Clemastina (Tavegil®) vía intramuscular 1 ampolla, es una excelente opción. También se emplea tradicionalmente otros medicamentos que incluyen Difenhidramina 25 - 50 mg vía intravenosa combinada con Ranitidina 50 mg vía IV 150 mg vía oral, dado que bloquear $\mathrm{H} 1$ y H2 es más efectivo que el bloqueador $\mathrm{H} 1$ solo.

- Los esteroides, controlan reacciones tardías, por tanto no sirven solos en la reacción inmediata en el caso de una reacción anafiláctica. Pero suministrar esteroides como Dexametasona $4 \mathrm{mg}$ u $8 \mathrm{mg}$ IM dependiendo de la severidad de los síntomas es conveniente para bajar la inflamación y si hay signos como broncoespasmo, por 1 o 2 días $\mathrm{c} / 8 \mathrm{~h}^{18}$. - Controlar el dolor con un analgésico potente dependiendo de la severidad del mismo.

- Antibioticoterapia para prevenir una infección secundaria de 7 a 10 días

- Cuidados paliativos con terapia térmica, enjuagues con solución salina o con soluciones cicatrizantes ${ }^{14}$.

- Monitorear al paciente continuamente e informarle a quien llamar o donde acudir en caso de complicaciones, cuando el manejo es ambulatorio ${ }^{10}$.

- Lesiones mayores podrían requerir intervenciones quirúrgicas para hacer un desbridamiento de tejido necrótico y aplicar técnicas de regeneración.
- Al final, darle instrucciones verbales y escritas de autocuidado.

\section{RECOMENDACIONES PARA EVITAR UN ACCIDENTE CON NAOCL DURANTE EL TRATAMIENTO DE CONDUCTOS RADICULARES}

Si se va a utilizar esta sustancia como irrigante, realizar una adecuada historia clínica y tener presenta si el paciente tiene antecedentes personales o familiares de algún tipo de alergia a sustancias varias, y preguntar por contactos previos con hipoclorito ${ }^{12}$. Es fundamental utilizar lentes de protección tanto para el paciente como para el clínico.

Idealmente hacer aislamiento con dique de goma especialmente si se va a utilizar una sustancia irrigante toxica; emplear la aguja adecuada calibre 27 o 30 con salida lateral y llegar máximo hasta $1 \mathrm{~mm}$ antes del foramen tratando de no obliterar totalmente el conducto para facilitar la circulación del irrigante e introducir lentamente la solución entre $0.5 \mathrm{~cm}$ a $2 \mathrm{~cm}$ por vez, evitando impulsar la sustancia a través del foramen apical ${ }^{19}$. También es recomendable usar sistemas de irrigación por presión negativa.

No utilizar $\mathrm{NaOCl}$ en pacientes de riesgo: ápices inmaduros, resorciones patológicas, perforaciones accidentales ${ }^{13}$; Lavar el $\mathrm{NaOCl}$ diluyéndolo con solución salina ${ }^{12}$.

Finalmente todo odontólogo que realice tratamientos de conductos radiculares debe tener un protocolo de manejo de complicaciones con hipoclorito ${ }^{10,13}$.

\section{CARACTERÍSTICAS IDEALES DE UN IRRIGANT E ENDODÓNTICO}

Antibacteriano idealmente bactericida y/o bacteriostático, pues se ha considerado que el éxito o fracaso de un tratamiento de conductos, depende del control de los microorganismos y sus toxinas, asumiendo que si no se logra exterminar dichos microorganismos se puede conducir al fracaso endodóntico. Recientemente se encontró que los microorganismos presentes dentro de los diferentes ecosistemas del ser humano como la boca, el colon, los genitales externos, etc., en un paciente con un sistema inmunológico equilibrado mantendrían estable las interacciones entre los microorganismos nativos y los patógenos. Si tal equilibrio 
se rompe habría efectos deletéreos orgánicos por la dominancia del patógeno sobre el sistema inmune del paciente, de tal manera que no es suficiente eliminar los microorganismos con una sustancia irrigante, sin sopesar el estado de equilibrio fisiológico del paciente que pueda o no contribuir en la erradicación de la infección.

Baja toxicidad. Idealmente el irrigante no debe ser toxico para el ser humano, ni agresivo con los tejidos blandos.

Solvente de residuos orgánicos e inorgánicos. Siempre se ha idealizado el hipoclorito por su capacidad para desnaturalizar las proteínas y disolver residuos de tejido pulpar en áreas inaccesibles con accidentes anatómicos en los conductos, pero esta característica lo hace altamente toxico.

Baja tensión superficial. Esta propiedad permite que el irrigante fluya dentro los canalículos intrarradiculares a veces inaccesibles, mientras más baja tensión superficial, mayor capacidad de penetrar en los túbulos dentinales. A algunos irrigantes se les ha adicionado alcohol lo que disminuye la tensión superficial y lo hace más útil como irrigante pero no se asegura que mejore la limpieza ${ }^{16}$.

Lubricante. Cualquier líquido puede tener esta propiedad, aunque algunos podrían ser más eficaces, facilitando el deslizamiento del instrumental dentro del conducto.

Fácil aplicación. Un irrigante idealmente debe tener esta cualidad.

Acción rápida. Dentro del conducto, sus propiedades deben permitir facilitar el trabajo sin que sus características químicas y físicas retarden o no facilitar el trabajo ${ }^{11}$. Sumado a esto debería considerarse la acción continuada del irrigante, puesto que una acción antimicrobiana localizada en el conducto favorece un tratamiento a largo plazo sin tener que usar antibióticos sistémicos; esta es una condición ideal y difícil de obtener con los métodos de irrigación actuales.

lgunas soluciones irrigantes usadas actualmente son: Compuestos halogenados, Soluciones de hipoclorito $(\mathrm{NaOCl})$ desde $0.5 \%$ hasta $5.25 \%$ :

$\mathrm{NaOCl}$ al 0.5\% Solución de Dakin.
$\mathrm{NaOCl}$ al 1\% + ácido bórico Solución de Milton.

$\mathrm{NaOCl}$ al 2\% Solución de Labarraque.

$\mathrm{NaOCl}$ al 4-6, 5\% Soda clorada doblemente concentrada

\section{$\mathrm{NaOCl}$ al 5.25\% Preparación oficial USP}

Gluconato de corhexidina al 2\%. Usada inicialmente como antiséptico pre quirúrgico para el clínico y el paciente, luego se usó para desinfectar la boca y a partir de 1970 se popularizó como enjuague bucal; en 1975 Baker y cols la consideraron viable como irrigante de conductos (al $2 \%$ ). En 1982 Delany y cols comprobaron que era eficaz antibacteriano en tratamiento de conductos, ahora se usa para irrigación subgingival, en geles, dentífricos y chicles para ${ }^{17}$ combatir la caries, la enfermedad periodontal y como medicamento intraconducto, además que es poco toxica y al ingerirse se elimina por materias fecales, luego de su absorción por el tracto digestivo se elimina por hígado y riñón. Es ampliamente bactericida a altas concentraciones y bacteriostático a bajas concentraciones. Como irrigante de conductos se usa en concentraciones desde $0.12 \%$ a $2 \%$. A bajas concentraciones se demora más para actuar. Como medicamento intraconducto puede evitar la sobreinfección por tiempo prolongado. A diferencia del hipoclorito no disuelve el tejido orgánico. Una desventaja de su uso es que manejado por tiempo prolongado pigmenta la lengua, los dientes y las restauraciones y puede alterar el gusto ${ }^{11}$. Basrani y col en el $2007^{20}$ mezclaron clorhexidina e hipoclorito a altas concentraciones y concluyeron que se formaba un precipitado cancerígeno. Concluyó que el hipoclorito debía tener una concentración al $2.5 \%$ o menos y la clorhexidina debe ser al $0.2 \%$ para evitar efectos citotóxicos.

Quelantes. Usados para la preparación biomecánica de conductos atrésicos y/o calcificados. Realmente no son soluciones irrigantes sino auxiliares para ensanchar conductos ${ }^{21}$.

$M T A D$. Es un irrigante nuevo, donde se mezcla del isómero de tetraciclina (doxiciclina) + un ácido (ácido cítrico) + un detergente (Tween 80). Se propone emplearlo combinado con $\mathrm{NaOCl}$ al $1.3 \%$ en una proporción de $3 / 4$ partes más de tiempo con hipoclorito por $1 / 4$ de tiempo del MTAD. La doxiciclina de éste tiene alta afinidad por el esmalte dental y para matar el E, faecalis (un microorganismo 
anaerobio facultativo comúnmente encontrado en infecciones de conductos radiculares persistentes asintomáticas, que tiene la habilidad de competir con otros microorganismos, invadir túbulos dentinales y sobrevivir sin 18 nutrientes, es considerada una especie muy resistente y causal de fracasos endodonticos ${ }^{11}$.

Otras opciones. Aunque no hay estudios publicados sobre sus efectos

- Agua destilada esterilizada

- Peróxido de Hidrogeno 10 volúmenes.

- Suero fisiológico ${ }^{11}$.

- Anestésicos como Procaína al 1\% o 2\% y Lidocaína al $2 \%$ con y sin epinefrina: Los anestésicos locales son generalmente estructuras aminoéster o amino-amida unidas a un grupo hidrofílico (amina secundaria o terciaria). ${ }^{22-23}$

- La Procaína es un anestésico local del grupo de los amino ésteres. (éster acido $\mathrm{p}$-aminobenzoico) de metabolismo hepático, acción rápida, eliminación por orina y sirve principalmente, para tratar el dolor de ciertas patologías. Tiene efectos biorreguladores que estabiliza la función que esté disfuncional, ya que es el medicamento usado en la terapia neural y se ha comprobado que tiene efecto antibiótico al inhibir varias cepas in vitro ${ }^{23}$. - La Lidocaína o Xilocaína pertenece al grupo amino-amida, entre los que también se encuentran otros anestésicos locales. Tiene efecto biorregulador similar al de la Procaína ${ }^{22}$.

En nuestra consulta hemos empleado irrigantes diferentes al hipoclorito como son los anestésicos, los cuales proveen de los siguientes beneficios: reducir los riesgos de toxicidad; propiciar el control de algunas cepas de bacterias durante el periodo de tiempo que se requiera para terminar el tratamiento de conductos, disminuir o eliminar la sensación dolorosa durante la instrumentación y finalmente, favorecer la biorregulación de los tejidos al reducir la citotoxicidad.

Luego de abordar el conducto previa anestesia y apertura cameral, remover los detritus intracamerales con instrumentación biomecánica y realizar la irrigación con Procaína o Lidocaína con o sin epinefrina. Como cualquier químico no está exento de generar una reacción anafiláctica sobre todo si se instila a través del ápice radicular, pero su contacto con el organismo tiene muchos beneficios documentados en la terapia neural, además de reducir el riesgo de dolor intra y posoperatorio.

\section{DISCUSIÓN}

Similar al caso documentado en este artículo, Raffo Lirios y cols., en 2010 reportaron una mujer de 20 años que sufrió una reacción anafiláctica al ser irrigado los conductos del diente 18 con hipoclorito de sodio $(\mathrm{NaOCl})$ presentando dolor agudo tipo ardor, seguido de un edema inmediato en la zona afectada (hemicara izquierda) que duró hasta el octavo día, al cabo del cual se presentó una paresia ligera en la zona naso geniana superior, y que empezó a mejorar a los 20 días, con recuperación total a los 40 días 24 (Raffo Lirios y col, 2010) y manejo ambulatorio.

En el caso de nuestra paciente, la reacción también fue inmediata pero más severa, apareciendo igualmente una sensación de ardor o un dolor quemante insoportable, un edema inmediato progresivo y difuso que comprometió no solo el lado afectado sino ambos lados de la cara y tejidos blandos que acompañan ambos maxilares. También aparecen rápidamente síntomas orgánicos, neurológicos y cardio-respiratorios; estos síntomas se atenuaron en las primeras tres horas bajo el manejo hospitalario y un manejo agresivo 20 farmacológico, pero el edema sigue progresando y se difunde a áreas vecinas, para luego aparecer los hematomas en el transcurso de 4 días.

En ambos casos el agente causal fue el hipoclorito de sodio, el cual según Teixeira C, $2005^{25}$ y De Vasconcelos B, $2007^{26}$, es la sustancia más usada como irrigante de conductos a diversas concentraciones, el cual se usa solo o alternando con otras sustancias, a pesar de que se sabe que no remueve completamente la parte inorgánica del barrillo dentinario ${ }^{27}$, y que en conductos estrechos no humedece completamente las paredes del canal ${ }^{28}$.

Torres LM y Torres $2014^{27}$ anotan cambios estructurales que generan en la dentina, los irrigantes como el hipoclorito al 5.25\%, el EDTA al $17 \%$ y la clorhexidina al $2 \%$, haciendo una reducción de su microdureza ${ }^{29}$, quedando el diente propenso a fractura pos tratamiento endodóntico.

Shabahang et al $2003^{30}$, realizaron un experimento para comparar la efectividad del $\mathrm{NaOCl}$ al $5.25 \%$ con MTAD en dientes extraídos y contaminados con saliva y luego de ser tratados con ambas soluciones, 23 dientes tratados con hipoclorito seguían 
infectados, mientras que solo 1 de 60 dientes tratados con MTAD seguía infectado, resultando el MTAD un excelente irrigante y menos citotóxico que la mayoría de los irrigantes. También el uso de anestésicos orales como irrigantes intraconducto reducen los riesgos de citotoxicidad al contacto con los tejidos duros y blandos, sin poner en peligro la estructura del diente, y mejorando la sintomatología dolorosa que suele acompañar estos tratamientos. En su defecto otros irrigantes menos tóxicos como la clorhexidina, la solución salina, y el agua destilada generan menos riesgos de efectos nocivos.

La Sociedad Europea de Endodoncia ${ }^{31}$ promulga el uso restringido de antibióticos en los tratamientos endodónticos. Ellos recomiendan asumir una conducta responsable, con el fin de evitar la aparición de resistencia bacteriana y reducir la contribución del odontólogo a generar un efecto secundario en el uso indebido de dichos medicamentos.

Aun así, en nuestro trabajo clínico hemos manejado el desbridamiento químico mecánico empleando penicilina benzatinica mezclada en una tercera parte con el Hidróxido de calcio, y mezclados con glicerina que da mayor estabilidad, en el manejo temporal del conducto luego de del desbridamiento y mientras se realiza el tratamiento definitivo.

Con una experiencia de 20 años en esta práctica podemos dar testimonio de tener excelentes resultados sin ninguna complicación, sin efectos negativos y con alivio de la sintomatología dolorosa máxima. A pesar de que el uso de antibióticos tópicos durante el tratamiento del canal radicular no está apoyado por la evidencia documentada, la mejoría clínica de los síntomas del paciente puede determinar la efectividad del tratamiento endodóntico. La penicilina benzatínica ofrece la virtud de no ocasionar decoloración del conducto y se ha documentado que la mayoría de los microorganismos tienen sensibilidad a este antibiotico ${ }^{32}$.

Cope et al (2014), ${ }^{33}$ argumentó que, la falta de circulación sanguínea en el canal radicular evita que los antibióticos lleguen a la zona apical y considera que son ineficaces para eliminar los microorganismos alrededor del peri ápice, citado por Segura-Egea JJ. et al (2016) ${ }^{32}$ En lugar de ser una desventaja, consideramos que un antibiótico intra-conducto desinfecta el canal radicular sin 22 hacer un efecto sistémico que puede ocasionar los discutidos efectos secundarios.

Los antibióticos se han empleado para desinfectar conductos radiculares en procedimientos endodónticos regenerativos (REPs) en dientes con pulpas necróticas inmaduras y periodontitis apical con excelentes resultados. Diógenes et al. $2013^{34}$ menciona que el sistema de canales se desbridó químicamente con hipoclorito de sodio al 5,25\% ( $\mathrm{NaOCl} 5,25 \%$ ) sin instrumentación seguido de la colocación de una pasta triple de antibiótico menciona que en estos casos se ha hecho mínimo desbridamiento mecánico y Kontakiotis EG 2015 anota que el medicamento intracanal han sido utilizados en casi todos los informes de casos publi$\operatorname{cados}^{35}$. Sin embargo, la literatura no menciona si esta práctica genera algún riesgo de efectos secundarios.

Es poca la información encontrada en la literatura sobre el manejo de antibióticos locales intraconducto, lo cual puede deparar varios beneficios en este tipo de tratamientos como es el de no suministrar antibiótico sistémico a regiones del organismo en donde no se necesita y la optimización del régimen terapéutico, lo cual implica una mejoría en la práctica de la prescripción antibiótica, y por ende una práctica endodóntica más segura ${ }^{36-37}$.

\section{CONCLUSION}

$\mathrm{El} \mathrm{NaOCl}$ ha sido empleado como irrigante intraconducto en la terapia endodóntica desde el siglo pasado, antes de que aparecieran los antibióticos en la medicina. A pesar de los estragos que ha generado en los tejidos de los pacientes y del avance de ciencia a nivel de sustancias más adecuadas para este fin, permanece en la práctica odontológica como la primera elección en los irrigantes. Algunas reacciones desfavorables han ocurrido en los pacientes por falta de cuidado en el empleo del irrigante, pero muchas otras han sido por la toxicidad que posee esta sustancia para los tejidos vivos. Es por ello que en este artículo se argumenta una práctica de irrigación alterna local, con el fin de generar la discusión sobre si es adecuado continuar con el uso del hipoclorito de sodio en tratamiento endodóntico, o si son necesarias futuras investigaciones en este campo, que amplíen nuestras medidas terapéuticas.

La Sociedad europea de endodoncia recomien- 
da ser cuidadoso en el uso indebido de los antibióticos, sin embargo estos se han empleado de rutina algunos tratamientos como el regenerativo con pulpas necróticas inmaduras y periodontitis apical, reconocido como un uso valido. Nosotros hemos empleado los antibióticos intra conducto como parte el desbridamiento químico temporal previo al tratamiento definitivo con excelentes resultados y aunque esto está poco documentado en la literatura, y no considerado como apropiado, el uso racional de un profesional puede sopesar los riesgos versus los beneficios.

\section{BIBLIOGRAFIA}

1. Pashley EL, Bridson NL, Bowman K, Pashley $\mathrm{DH}$. Cytotoxic effects of $\mathrm{NaOCl}$ on vital tissue. J Endod. 1985;11:525-28

2. Crane AB. A Practicable Root Canal Technique. 1st ed. Philadelphia, Pa: Lea $E$ Febiger; 1920:69.

3. Sampson HA, Munoz-Furlong A, Bock SA, Campbell RL, Adkinson NF Jr, Branum A. et al. Symposium on the definition and management of anaphylaxis: summary report. J Allergy Clin Immunol. 2005; 115:584-92.

4. Sampson HA, Munoz-Furlong A, Campbell RL, Adkinson NF Jr, Bock SA, Branum A. et al. Second symposium on the definition and management of anaphylaxis: summary report - Second National Institute of Allergy and 24 Infectious Disease/Food Allergy and Anaphylaxis Network Symposium. J Allergy Clin Immunol. 2006;117:391-97

5. Moro Moro M, Tejedor Alonso MA, Hernández JE, Múgica García MV, Rosado Ingelmo A, Vila Albelda C. Incidence of Anaphylaxis and Subtypes of Anaphylaxis in a General Hospital Emergency Department. J Investig Allergol Clin Immunol. 2011; Vol. 21(2): 142-49

6. Ellis AK, Day JH. Diagnosis and management of anaphylaxis. CMAJ. 2003;169(4):307-12

7. Ellis AK, Day JH. Anaphylaxis: diagnosis and treatment. Allergy Asthma. 2000;13(3):22-35

8. Camargo Assis FM. Alergia al látex periopera- toria. Presentación de casos. Universitas Médica. 2006; 47 (1):96-99

9. Mehra P, Clancy Ch, Wu J. Formation of a facial hematoma during endodóntico therapy. JADA. 2000; 131 (1):67-71

10. Mehdipour O, Kleier DJ, Averbach RE. Anatomy of Sodium Hypochlorite Accidents. Compendium. October 2007;28(10):544-50

11. Magallanes- Aguilar VL. Soluciones irrigantes en endodoncia. Universidad peruana Cayetano Heredia. 2010; 1-61

12. Neira Castillo MJ, Meneses Guzmán JP. Accidentes por Hipoclorito de Sodio en Endodoncia Protocolo de Atención. Publicación Científica Facultad de Odontología. Rev. Odovtos-Int J Dent Sc. Universidad de Costa Rica. 2005; (7):5-7

13. Juárez RP, y Lucas ON. Complicaciones ocasionadas por la infiltración accidental con una solución de hipoclorito de sodio. Revista ADM. 2001;58(5):173-76 25

14. Battrum DE, Gutmann JL. Implications, prevention and management of subcutaneous emphysema during endodontic treatment. Endod Dent Traumatol. 1995; 11:109-14

15. Liatiri ST. Subcutaneous Emphysema after Root Canal Therapy. Balk J Stom. 2012; 16(1):10-15

16. Lambrianidis ThP. Emphysema. In: Lambrianidis Th (ed). Risk management in root canal treatment. Thessaloniki: University Studio Press. 2001; 323-36

17. Caliskan M, Turkun M, Alper S. Allergy to sodium hypochlorite during root canal therapy. Int. Endod. Journal. 1994, 27: 163-67.

18. Simons FER, Gu X, Simons KJ. Epinephrine absorption in adults: intramuscular versus subcutaneous injection. J Allergy Clin Immunol. 2001; 108(5):871-3.

19. Sabala C, Powell S. Sodium Hypochlorite injection into periapical tissues. J. Endod. 1989; 15 (10):490-92 
20. Basrani BR, Manek S, Sodbi R, Fillery E, Manzur A. interaction between Sodium Hypochlorite and Clorhexidine Gluconate. J Endod. 2007; 33(8): 966-69

21. Leonardo M. Endodoncia. Preparación biomecánica de los conductos radiculares. Definición y concepto, finalidad, importancia. Recursos convencionales para su aplicación: medios químicos y medios físicos. In: tratamiento de conductos radiculares. Principios técnicos y biológicos. Editorial Artes Médicas, Latinoamérica, Sao Paulo, Brasil 2005; I: 435-76

22. Bertram G. Katzung; Susan B. Masters; Anthony J. Trevors (12. Ed.). Farmacología básica y clínica. New York: McGraw Hill-Lange. 2012; 449-63 26

23. Jiménez JC, Cárdenas ML. Procaína, epigenética y terapia neural en el cáncer, ¿una alternativa terapéutica? Méd. UIS. 2011;24:165-71

24. Raffo Lirios M, Torres Batista R, Domínguez Viña M. Accidente por difusión de hipoclorito de sodio durante la terapia endodóntica. Actas Odontológicas. 2010; 7(1):50 - 5

25. Teixeira C, Felippe M, Felippe W. The effect of application time of EDTA and $\mathrm{NaOCl}$ on intracanal smear layer removal: an SEM analysis. Int Endod J. 2005; 38(5): 285- 90

26. De Vasconcelos B, Luna-Cruz S, De-Deus G, de Moraes I, Maniglia-Ferreira C, Gurgel-Filho E. Cleaning ability of chlorhexidine gel and sodium hypochlorite associated or not with EDTA as root canal irrigants: a scanning electron microscopy study. J Appl Oral Sci. 2007; 15(5): 387-91.

27. Torres LM, Torres C. Caracterización de la dentina tratada endodónticamente: una revisión. Rev Fac Odontol Univ Antioq. 2014; 25(2): 372-88.

28. Zhang K, Tay F, Kim Y, Mitchell J, Kim J, Carrilho $M$ et al. The effect of initial irrigation with two different sodium hypochlorite concentrations on the erosion of instrumented radicular dentin. Dent Mater. 2010; 26(6): 514-23.

29. Oliveira LD, Carvalho CA, Nunes W, Vale- ra $\mathrm{MC}$, Camargo $\mathrm{CH}$, Jorge $\mathrm{AO}$. Effects of chlorhexidine and sodium hypochlorite on the microhardness of root canal dentin. Oral Surg Oral Med Oral Pathol Oral Radiol Endod. 2007; 104(4): e125-128.

30. Shabahang, Shahrokh et al. Effect of MTAD on Enterococcus faecalis-Contaminated Root Canals of Extracted Human Teeth. J. Endod. 2003; 29 (9): 576 - 7927

31. European Society of Endodontology developed by: Segura-Egea JJ, Gould K, Hakan S en B, Jonasson P, Cotti E, Mazzoni A, Sunay $\mathrm{H}$, Tjäderhane L, Dummer PMH. European Society of Endodontology position statement: the use of antibiotics in endodontics. Int Endod J. 2017; 1-6

32. Segura-Egea JJ, Gould K, Hakan S en B, Jonasson P, Cotti E, Mazzoni A, Sunay $\mathrm{H}$, Tjäderhane L, Dummer PMH. Antibiotics in Endodontics: a review. Int Endod J. 2016; 1-16

33. Cope Al, Chestnutt IG. Inappropriate prescribing of antibiotics in primary dental care: reasons and resolutions. Prim Dent J. 2014; 3(4): 33-7

34. Diógenes A, Henry MA, Teixeira FB, Hargreaves K.M. An update on clinica regenerative endodontics. Endod Topics. 2013; 28: 2-233

35. Kontakiotis EG, Filippatos CG, Tzanetakis GN, Agrafioti A. Regenerative endodontic therapy: A data analysis of clinical protocols. J Endod. 2015; 41(2): 145-54

36. Ventola CL. The antibiotic resistance crisis: part 1: causes and threats. Pharmacy and Therapeutics. 2015; 40(4):277-83.

37. Ventola CL. The antibiotic resistance crisis: part 2. Pharmacy and Therapeutics. 2015; 40 (5): 344-52.

\section{AUTOR DE CORRESPONDENCIA:}

Martha Lucia Marín Botero.

Correo electrónico: marthaluciamarin@gmail.com Universidad de Antioquia, Facultad de odontología.

Calle 64 \# 52-59

Teléfono: $(+574) 2196772$

móvil: (+57) 3147517508 y (+57) 3006589543 